ly, then the institutions are not performing as they should. By that criterion, the preeminent instance of government failure is now, and has been for a decade or more, our outrageous budget deficit. What has been wrong with our institutions on this question? Why can't we do better than a Gramm-Rudman-Hollings Act and a summit meeting that only papers over the problem? Why has the government been so impotent? What are the institutional remedies? What about divided government? That has seemed to me to be at the bottom of most of our problems, as I have written elsewhere, because it not only makes for deadlock and delay but destroys the responsibility and accountability that unified party government offers. Mayhew doesn't find the record of divided government to be all that bad, but he admits to methodological difficulties in making his assessment.

Anyway, the appraisal, reform, and redesign of institutions is the great challenge for political science today, in my view, and especially for those in our discipline who live and work at or near our national capital. I hope we will rise to the challenge and bear down on these questions of institutional performance and institutional failures and inadequacies. And, when we do, let's have those concluding chapters setting forth our recommendations.

\title{
Running the Good Race, Part 1* \\ High Anxiety: Some Lessons for Graduate Students Entering the Profession
}

\author{
John D. Harman, St. John Fisher College
}

\begin{abstract}
Editor's Note: From time to time PS has featured articles advising job candidates and junior faculty members on how to run a good employment race in the academic market. Beginning with this issue, we will publish a series of articles on job finding, teaching, publication, promotion and tenure. Some of the articles will be new material, others will be updates of previously published essays. You are encouraged to submit articles to the series if you see areas which have been overlooked or deserve more attention.
\end{abstract}

A fter preliminary or comprehensive examinations have been successfully completed, questions about employment after graduation naturally arise. "What kind of department should I apply to?" and "What will they expect of me?" are two crucial ones. Answers to these should take into account the following points.

First, the two main aspects of political science are research and teaching. Research generally translates into inquiry which results in the delivery of papers at scholarly conferences, and the publication of books and articles in scholarly journals. It also often includes the securing of grants from government or private sources to support this inquiry, an activity which brings additional resources into the college by helping to pay for the researcher's "institutional overhead" expenses (secretaries, fringe-benefits, building and maintenance costs, etc.). Teaching consists primarily of the preparation and administration of coursework, but can include activities such as the supervision of internships, independent study projects, and graduate work, advising, reading courses or tutorials, and the like.

Second, while colleges differ tremendously in the emphasis they place on these two aspects, they generally fall into three groups-those which emphasize research, those which emphasize teaching, and those which expect both. The key to differentiating them lies in the number of courses required for a full load and the amount of support given to research and "professional activities" (associated with dissemination of the results of research)-travel money, computer access, copying privileges, telephone and mailing support, teaching and research assistants, and clerical support. Research-oriented departments will usually have a minimal teaching load-two courses per semester/quarter is typical-and generous provision of professional activ-

\section{Note}

* Remarks presented at the spring meeting of the National Capital Area Political Science Association (in response to receipt of the Association's 1991 Pi Sigma Alpha Award), March 2, 1991

\section{About the Author \\ James L. Sundquist is a former Budget Bureau staff member, aide to a United States Senator, and Deputy Under Secretary of Agriculture who later spent 20 years (1965-85) as a Senior Fellow at the Brookings Institu- tion, two of those as director of the Govern- mental Studies Program. He is the author of six Brookings books, some of which contain recommendations for institutional reform.}

ity/research support. Teachingoriented departments will usually require substantially greater teaching loads-four or five courses per semester/quarter-with minimal professional support. Departments which expect both will fall between these two extremes.

Each prospective political scientist thus must answer for him/herself the question of how much commitment can be given to research or teaching. Teaching and research both require substantial effort to do well and are certainly fundamental intellectual pursuits. The answer arrived at regarding this question should determine the type of department to which one applies.

\section{Departmental Expectations}

The question of departmental expectations normally focuses on a specific event-the tenure decision. Most colleges grant tenure-permanent appointments from which professors cannot be fired without cause -after some probationary period, in most cases six years. This often coincides with the decision to promote assistant professors, typically to the associate professor level. Most also must release, or cannot reappoint, 
faculty whom they do not tenure. The result is an "up or out" system at most colleges.

Tenure decisions are usually based on a weighted combination of factors. Many colleges cite three areas in which faculty performance is assessed -teaching, research (or "scholarly activity"), and service. This last is often a catch-all which includes service within the department, college or university on committees or in special capacities (advisor, director of a special program, etc.). It may also include service in the community outside the college or university, e.g., as an officer in a community organization. While such formal documents as faculty statutes may say that equal weight will be given to these factors, this does not always appear to be the case. Instead, the decision will often depend upon teaching or research performance, with reference to service as a confirmation of the assessment based on these factors. Nonetheless, attention to these three areas (or whatever areas are described in the formal documents of an institution about the tenure decision) will be a prudent measure.

It should also be noted that a favorable departmental recommendation, while normally a necessary condition for promotion or tenure, is rarely sufficient. The final decision on these matters usually rests further up the line, at the college or university level. There are opportunities, as a result, for factors in addition to the merits of one's case to determine the outcome of the process. Some tenure decisions, in other words, are political, involving questions about power and resource allocation in the larger academic community. There is often no way to combat such circumstances, except to insure that the department has a strong case (can say as many good things about one as possible) when it recommends promotion or tenure.

Evaluation of teaching varies widely. In some departments it may be based on impressions gleaned from conversations with students, colleagues and the person being evaluated. In other departments teaching evaluation is a highly structured process, complete with formal surveys of students, self-evaluations, and classroom observation. The majority of departments are likely to fall between these extremes. Where the process of teaching evaluation is unstructured, improvement on a weak evaluation will be difficult, since the basis of the evaluation will be unclear. Where the process is more structured, improvement may be possible, especially where the evaluation is combined with an attempt to provide assistance.

Nonetheless, teaching evaluation is a controversial process, because there is often fundamental disagreement about what the essential elements of good teaching are. Lack of agreement about such questions contributes in many cases to the perception that the teaching evaluation pro-

\section{. . a favorable depart- mental recommendation, while normally a necessary condition for promotion or tenure, is rarely sufficient.}

cess, no matter how structured, is essentially subjective and liable to be influenced by how well the evaluators like or get along with the person being evaluated.

In contrast, the evaluation of research seems much more straightforward. The basic measure is the number of articles or books one has published. There are many complications to this, however.

When a published article is evaluated, several distinctions are generally applied to determine its weight or value. The first concerns the subject of the article. Articles which primarily review existing research (including survey articles, reviews of topic areas, and book reviews) are weighed less heavily than those which involve original research. A second factor is length. Full-scale essays10-15 pages typeset-weigh more heavily than "research notes." A number of distinctions can be made as to the type of publication in which the article appears.

The fundamental distinction is the difference between "refereed" and "non-refereed" publications, primarily journals. "Refereed journals" are those in which the editor sends an author's manuscript out (usually) anonymously to expert readers in the field. This process of "blind reading" ideally enables the readers to assess the worth of the article unbiased by the author's reputation (or lack of one) and to make an objective recommendation to the editor regarding publication. The decision to publish an article in such a journal thus reflects, again ideally, a judgement by experts as to the significance and quality of the writing and the research reported in the article. When an article appears in a nonrefereed publication, such as an edited book or in a journal that solicits articles, there may be less confidence in the expert judgement such publication represents.

There are more and less prestigious journals in any area. The "leading" journals are those with reputations for "'high quality," and for being the most selective in accepting articles. Almost all are refereed and have high rejection rates. An article published in such a journal will often enhance a departmental evaluation considerably.

Books are subject to similar evaluation guidelines. Reviews of existing research (such as textbooks) often count less than original work, unless they employ a highly innovative format. Work as the editor of a volume counts less than being the author. The most prestigious presses tend to be the scholarly or "university presses." At the other end of the scale are the so-called "vanity presses"--those that will publish a manuscript for a substantial fee or that require a "guaranteed order" for a certain number of copies in order to publish.

In addition to publications, most research-oriented departments encourage the range of professional activities that accompanies publication-the delivery of scholarly papers at conferences, service in professional organizations, appointment to editorial boards of journals or service in some other capacity.

Assessing which of these expectations exist in a given department is part of the interview process. Most departments are open about these 
matters, although the precise nature of such expectations can often change over the course of one's employment. These expectations are also conditioned by the expectations and records other departments in the college have of the candidates they put forward for tenure. Since these expectations will rarely decline, it is wise to expect some inflation of requirements.

It is prudent to determine as much as possible about the teaching and research expectations of departments in which one has an interest. This will enhance the beginning political scientist's ability to make a rational decision about employment and the likelihood of meeting the employing department's expectations. This brings us to the second aspect of this discussion.

\section{"How Can I Possibly Do What They Want?"}

Meeting the expectations outlined above requires planning and effort, whether the focus is on teaching or on research. Most people will be expected to do both reasonably well and present a creditable record for a tenure decision. How can these things be accomplished in the short span of six or seven years?

The key lies in a systematic approach to all activities-teaching, research and publication. We will begin with teaching. I will not attempt to address all the elements of good teaching-there are libraries on the topic in the education departments of most colleges and universities. Instead, I will briefly mention some typical problem areas and suggest solutions.

Teaching methods present a problem to most political scientists because they are rarely specifically dealt with in the course of graduate preparation. Typically, graduate students serve one or more terms as teaching assistants, with varying degrees of instruction in the mechanics of course construction and presentation by their supervising professors. An alert graduate student, however, can generally discern the broad parameters of organizing courses by consulting a variety of syllabi and the professors who draft them. Among the important considerations are the following: How to choose themes around which to structure a course; how to select texts (levels of difficulty, expectations about student abilities, etc.); how to schedule lectures and exams into a syllabus; how to write lesson plans and lectures; how to stimulate and manage class discussions; how to integrate outside readings into material from texts and lectures; how to construct, administer, and grade various types of exams and other assignments; how to apply different types of grading strategies to assess student progress; how to deal with such problems as wide disparities in student backgrounds and abilities.

In addition to one's professors in graduate school, there are other sources to consult. The Political Science Teacher in PS is a forum dealing with these concerns. Syllabus exchanges are sometimes organized as a part of regional or state association meetings. Discussion with colleagues can be useful as well, provided it is not viewed as an admission of incompetence and subsequent poor evaluation as a teacher. One way of getting around this perception might be to organize a regular colloquium on teaching methods where many teachers can address these issues together with less chance of anyone being singled out for adverse evaluation. Further, preparation for preliminary or comprehensive examinations can serve as an occasion to practice organizing courses in the areas in which one will be examined. This not only helps in surveying the literature in the area, but also in identifying overall themes or organizing concepts that can later serve as the basis for courses.

Finally, one problem that most will eventually face is the necessity of teaching a course outside of one's primary area of interest, and for which one may have had only cursory preparation. Where time does not permit taking six months for preparatory reading, such a course can be rapidly organized by consulting several of the leading textbooks in the field. This not only provides a review of the main controversies in the field, but usually a reasonably thorough bibliography of recent or classic works in the area and topics for lecture or discussion. Such measures cannot ultimately replace fundamental mastery of the literature, and are valid for preparation of undergraduate courses; but they provide a ready basis for more thorough subsequent preparation.

All graduate students have been exposed to various teaching strategies and teaching problems in their own graduate and undergraduate courses. Many will also have participated in research projects as research assistants and so will have a fair idea how research itself is conducted. (The latter is also the subject of coursework in most graduate curricula.) The very few will have had much experience in turning research into publications. As the topics of conference participation and publication are dealt with more thoroughly elsewhere, it will be sufficient to offer a few observations about them here.

As a way of understanding the research/publication cycle, consider graduate seminars. These frequently are organized in such a way that participants review and discuss ideas in which they all have common interests, select topics on which to write, present rough drafts to the other participants for critical review and try to incorporate the results of such review in the final drafts which are submitted to the instructor at the end of the course. In a highly compressed form this is the process by which research is generated and brought to a publishable state in the profession, with the place of the seminar participants taken by other agents and forumsdepartmental and nearby colleagues, professional society conference participants, and journal editors and their reviewers.

One of the most important aspects of departmental life, from the standpoint of the individual members, involves the exchange of ideas and feedback among colleagues and students. One of the advantages of a large department is the greater degree to which this can occur. This kind of exchange is very helpful in refining research and preparing it for publication.

Several points deserve attention here. First, this is why it is important to make an assessment during the interview process about intellecual 
compatibility with one's prospective colleagues. If there is no one in the department with whom to explore new ideas, with whom to engage in creative argument, in whose judgement one has some confidence about the soundness of argument and the worth of ideas, then the research/ publication process is made much more difficult to begin and to sustain. Second, the wider the circle of such colleagues, the richer and more exciting the resulting process. One should thus also seek compatible colleagues with whom to discuss ideas outside of one's department-in other departments and at other colleges in the area. Study groups, colloquia, informal organizations or local chapters of larger professional crganizations can also be utilized. Expansion of one's contacts in this way can help to offset lack of colleagues in a small department.

Once ideas have been put on paper and circulated in the local area, it is important next to present them in a more formal conference setting. Not only do conferences provide a wider audience with whom to explore arguments, but they also serve as evidence of scholarly activity.

The normal avenue for conference participation is through the annual meetings of national, regional, or state associations. Special conferences, convened and funded by grants from some agency or foundation, should not be overlooked, however, since the results are often published as a special volume of conference proceedings. Having one's proposal selected for presentation at such a conference can thus facilitate its publication. Sometimes the same thing happens at a regularly convened conference, where someone on a panel takes the initiative to edit the papers and comments to provide a separate volume or perhaps a special issue of a journal devoted to the panel topic. Journal editors attend conferences and will often invite submission of papers they found interesting to their journals. While editors rarely "guarantee" publication in their journals, such an invitation should be read as a commitment to expedited and sympathetic processing by the editor who issues it.

The more normal route to publication is a good deal bumpier and, from the author's standpoint, the journal publication process is extremely time-consuming. The time required for a manuscript to reach the readers after it is mailed by the author ranges from two to four weeks. To get from the readers to the editor again can take much longer-from one to three months, depending on the insistence of the editor. Authors will usually hear from the editor within two weeks of receipt of the final reader's evaluation. Thus an author can often expect a two- to six-month wait to hear about decisions on the manuscript.

This time-frame is further complicated by submission policies. The American Political Science Association and most journals condemn the practice of multiple submissionssending manuscripts for review to more than one journal at a time. (Law reviews are an exception to this rule. They expect multiple submissions, which are apparently the norm.) If the article is not accepted on the first submission, the entire process will have to be repeated. It is not unusual for one or two years to elapse before a manuscript is accepted for publication.

Some further cautions should be raised about this process. Rejection happens to everyone, so one should not become demoralized by it. Usually evaluations are fair and rest on the identification of genuine flaws in argument or method. The author can use the resulting comments to correct such flaws, thus improving the chances of subsequent acceptance. Sometimes rejection will occur, even though the readers have given a positive evaluation, because of recent publication by the journal of articles on the same topic and a desire by the editor to provide diversity.

Unfair rejections, however, do occur. An editor, or, more often, a reader, may be prejudiced against certain approaches or individuals. Where the editor is prejudiced, there is little an author can do beyond not sending that journal further manuscripts. Where a reader is the problem, however, calling this to the attention of the editor may result in evaluation by another reader.

A second caution concerns the time involved in the process, which can be reduced by some precautions.
Prior research and review of the contents of journals that publish in the area will reveal their focus through editorial statements and the topics of recent articles, enabling the author to select the most compatible journal. Such a review should also include the specific submission format-length restrictions, style conventions, number of manuscript copies, etc.-for various journals, which can then be kept in a card file for easy reference.

\section{Conclusion}

My objective to this point has been to provide some answers for two reasonable questions likely to be asked by prospective academic political scientists-"What am I expected to do?" and "How can I do it?" Part of what I have intended to convey is exactly how much work it takes to succeed in the field, regardless of the level or type of position. But I have also tried to give some suggestions as to how that work can be made more manageable than might at first glance appear.

A further lesson to be drawn is the importance of beginning the process while still in graduate school. Conferences attended, artices submitted and, if fortunate, accepted for publication all go a long way toward easing the transition from graduate student to serious scholar in the eyes of one's new colleagues. From this standpoint, securing a full-time teaching or research position before completing one's dissertation can be a major mistake.

A second, and more somber lesson for an aspiring scholar is that the barriers may be too high, the demands too great, for any reasonable hope of success. In some ways this is certainly true. There are enough elements of uncertainty and caprice to rule out a complacent expectation of success. Many people, good people, will not make it through the process. Some will fail to finish dissertations, will be overtaken by events and will be forced out into other pursuits. Others will quit after years of patient, frustrating struggle. Still others will be victims of patently unfair decisions. In short, the role of chance in the process is enormous. This, of course, is not a special curse 
of this discipline, but of academic careers in general. When the material rewards, in terms of salary and security, are matched against the effort, it may hardly seem worth it in any rational sense.

Yet there are some important compensations. In most cases, this career offers the prospect of being able to define one's own objectives and control the pace and content of one's labor. It offers the many rewards of teaching-making a difference in the lives of others, starting students on their own quest for knowledge, contributing to the betterment of community and so on. It often includes the opportunity to participate in work at the frontiers of knowledge about a critical dimension of human life. It almost always provides a lifetime's worth of intellectual challenges, often in company with help- ful and exciting people who encourage one to keep trying to meet those challenges. It can, in short, make life interesting. And for all of those that fall by the wayside, there are many others who make it through successfully.

Further, while it shares the liabilities of an academic life, a scholarly career in political science offers the same compensations. For many, this includes a measure of modest financial security with tenure. More importantly for most, whether in research or teaching, it offers the excitement of making a living by one's wits, of shaping events (occasionally) and minds (often) on the strength of pure intellectual energy.

For some, such compensations are enough rationally to offset the risks of failure this career entails. For others, there is no question of

\title{
Recruiting Minority Students for Academic Careers: The Role of Graduate Student and Faculty Mentors
}

\author{
Carlos E. Juárez, University of California, Los Angeles
}

In a recent issue of $P S$ (23: 229-232), Catherine Rudder called attention to various APSA projects designed to address the "pipeline" problem - the need to recruit minorities into graduate school and into the political science professoriate. With the anticipated shortage of faculty in the coming decade, there is a window of opportunity to bring more minority group members into the profession. The task of recruiting minority students for academic careers requires a concerted effort not only on the part of professional associations like the APSA (Garcia and Smith 1991) but more directly of faculty and graduate student mentors.

At the University of California, Los Angeles (UCLA), an innovative graduate mentorship program was initiated in the College of Letters \& Sciences during the 1990-91 academic year. The new Graduate Mentor Program (GMP) is designed to increase the number of faculty of color within educational institutions by encouraging talented minority students to consider academic careers. Often when these students pursue advanced degrees, they choose professional schools to prepare for careers in law, medicine, or business. Masters and Ph.D. programs in traditional academic disciplines are less likely to be considered. A GMP survey revealed that among the reasons for this was lack of knowledge about graduate school, the graduate application process, and the long-term rewards of graduate education.

The GMP program is an important step in the pipeline for academic careers as it strives to educate students about graduate school options. Experienced minority graduate students from different academic disciplines coordinate a wide range of support services for minority and low income students.

The need for a graduate mentor program arose out of recognition that a growing number of undergraduate minority students represent a significant pool of potential academic scholars. Figures from the Office of Academic Planning at UCLA reveal that in 1980 , the choice, since the alternatives are so infinitely less attractive as to be unthinkable while any hope of success remains. It is in the hope of saving these last committed aspirants that I have set these lessons down.

\section{Note}

*I am very grateful for assistance from several people in commenting on various drafts of this article. They include Paula Sage, Bob Heineman, Ted Bluhm, Mike Schatzberg, and Booth Fowler.

\section{About the Author \\ John D. Harman is an associate professor of political science at St. John Fisher College. A past president of the New York State Polit- ical Science Association, he is the author of several articles in political theory.}

freshman class at UCLA was $67 \%$ white and $33 \%$ ethnic minority. A decade later, the 1990 freshman class was the reverse: $36 \%$ white and $64 \%$ minority. Students of color now account for more than half of all UCLA undergraduates, making the campus, along with Berkeley, the most diverse research university in the nation. Yet despite this demographic change at the undergraduate level, graduate programs at UCLA and elsewhere remain provinces of white privilege.

\section{Graduate Student Mentors}

The GMP's Graduate Student Mentors provide individualized counseling and advice on all aspects of graduate school preparation. Throughout the year, various workshops and seminars are organized on topics relevant to graduate studies. These include workshops to explain the graduate school application process and familiarize students with options for financing graduate educa- 